\title{
FORMAÇÃO DO PROFESSOR DO CAMPO: O ESTÁGIO SUPERVISIONADO NO CURSO DE LICENCIATURA EM EDUCAÇÃO DO CAMPO/CIÊNCIAS DA NATUREZA, DO CAFS/UFPI
}

\section{Field teacher training: the supervised internship in the course of licensing in education of the field/natural sciences, of CAFS/UFPI}

Ágata Laisa Laremberg Alves Cavalcanti ${ }^{1}$ Antonia Dalva França-Carvalho ${ }^{2}$

\begin{abstract}
RESUMO: O presente estudo objetiva compreender a importância do Estágio Supervisionado para a formação de professores do campo, do curso de Licenciatura em Educação do Campo/Ciências da Natureza, do Campus Amílcar Ferreira Sobral (CAFS), da Universidade Federal do Piauí (UFPI). A análise e a reflexão do Estágio Supervisionado na LEdoC/CAFS está integrada à tríade ensino, pesquisa e extensão, de forma a possibilitar ao aluno estagiário, refletir sobre sua prática durante e depois do estágio, ao tempo que permite ao futuro professor, tornar-se pesquisador de sua prática. O estudo está pautado na perspectiva metodológica de Oliveira (2012); nas concepções sobre o Estágio Supervisionado propostas por Ghedin; Oliveira; Almeida (2015), Carvalho (2012), Pimenta; Lima (2004), dentre outros; além das legislações e do Projeto Político Pedagógico do curso. Os dados da pesquisa são provenientes da caracterização do Estágio Supervisionado na LEdoC/CAFS e da análise dos relatos de experiência apresentados pelos alunos nas disciplinas de Estágio Supervisionado II e IV. Estes revelam a importância dessa etapa na formação de professores do campo, pois possibilitam a reflexão sobre sua prática, articulando os saberes da docência, que lhes auxiliam na tomada de decisões e na resolução de problemas no contexto escolar. O Estágio Supervisionado na LEdoC/Ciências da Natureza tem buscado formar um professor do campo capaz de conhecer a teia de relações que há no espaço escolar; conhecer a dinâmica das instituições de ensino; compreender os limites e as possibilidades para o desenvolvimento do trabalho pedagógico; valorizar os conhecimentos e a cultura campesina; articular conteúdos científicos aos saberes da comunidade; desenvolver um olhar sensível do processo ensino e aprendizagem; além de encontrar caminhos e possibilidades condizentes com a realidade e as necessidades da escola do campo.
\end{abstract}

Palavras-chave: Estágio Supervisionado. Formação de professores. LEdoC. Professor do campo.

ABSTRACT: The present study aims to understand the importance of the Supervised Internship for the training of teachers in the field, in the Degree Course in Rural Education / Natural Sciences, at Campus Amílcar Ferreira Sobral (CAFS), at the Federal University of Piauí (UFPI). The analysis and reflection of the Supervised Internship at LEdoC/CAFS is integrated with the teaching, research and extension triad, in order to enable the trainee student to reflect on his practice during and after the internship, while allowing the future teacher to become if researcher of your practice. The study is based on the methodological perspective of Oliveira (2012); in the conceptions about the Supervised Internship proposed by Ghedin; Oliveira; Almeida (2015), Carvalho (2012),

\footnotetext{
1 Doutoranda em Educação pela Universidade Federal do Piauí (UFPI). Professora do Curso de Licenciatura em Educação do Campo (LEdoC)/Ciências da Natureza, da UFPI, Campus Amílcar Ferreira Sobral (CAFS), em Floriano (PI). E-mail: agatalaysa@ufpi.edu.br

${ }^{2}$ Doutora em Educação pela Universidade Federal do Ceará (UFC). Professora do Departamento de Fundamentos da Educação e do Programa de Pós-Graduação em Educação (PPGEL), do Centro de Ciências da Educação (CCE), Universidade Federal do Piauí (UFPI), Campus Ministro Petrônio Portella (CMPP). E-mail: adalvac@uol.com.br
} 
Pimenta; Lima (2004), among others; in addition to the laws and the Political Pedagogical Project of the course. The research data come from the characterization of the Supervised Internship at LEdoC/CAFS and the analysis of the experience reports presented by students in the disciplines of Supervised Internship II and IV. These reveal the importance of this stage in the training of teachers in the field, as they enable reflection on their practice, articulating the knowledge of teaching, which help them in decision-making and problem solving in the school context. The Supervised Internship at LEdoC/Natural Sciences has sought to train a teacher in the field capable of knowing the web of relationships that exist in the school space; know the dynamics of educational institutions; understand the limits and possibilities for the development of pedagogical work; valuing peasant knowledge and culture; articulate scientific content to the community's knowledge; develop a sensitive view of the teaching and learning process; in addition to finding ways and possibilities consistent with the reality and needs of the rural school.

Keywords: Supervised Internship. Teacher training. LEdoC. Field teacher.

\section{CONSIDERAÇÕES INICIAIS}

Nos cursos de licenciatura, o Estágio Supervisionado é um momento de aprendizagem da docência, por meio do exercício da prática docente, que articula diversos conhecimentos práticos aos teóricos aprendidos ao longo do curso. Caracteriza-se também, como um momento de análise do contexto real, sendo um elemento fundamental para a formação profissional, além de ser parte integrante do processo de formação inicial, pois consiste no espaço, por excelência, da relação dialética entre a teoria e a prática.

Entendemos que a formação do professor deve partir do exercício da análise e reflexão sobre a prática docente, de modo a desvelar o cotidiano escolar pela inserção do aluno estagiário no campo de atuação docente. Dessa forma, o Estágio Supervisionado constitui um componente curricular obrigatório essencial para formação de professores. Nesse sentido, ele é considerado uma importante etapa da formação docente, em que o aluno constrói, ao longo das experiências vivenciadas na docência, a sua identidade profissional.

Por isso, voltamos nosso olhar para a formação do professor do campo, no âmbito do Curso de Licenciatura em Educação do Campo. O desenvolvimento do Estágio Supervisionado possibilita aos futuros professores do campo, refletir sobre a educação que vem sendo ofertada aos alunos, considerando a valorização dos saberes de todos os sujeitos do campo, garantindo-lhes o direito a um ensino de qualidade na sociedade, por meio de uma educação emancipatória e transformadora.

O curso de Licenciatura em Educação do Campo é uma conquista das populações do campo, que tem como objetivo oferecer uma educação voltada para a realidade do trabalhador rural. Essa conquista foi garantida através das lutas dos movimentos sociais e sindicais do campo 
(GONÇALVES, 2016). Dessa forma, é preciso que o ensino seja voltado para a realidade dos alunos e que a escola do campo incorpore a luta do seu povo, a sua cultura, as suas memórias e que o campo seja reconhecido como lugar de vida, de produção, como um projeto de desenvolvimento. Assim, a formação do professor do campo deve ser pautada numa perspectiva libertadora, reflexiva e crítica, de forma a possibilitar o crescimento pessoal e profissional dos futuros docentes.

Segundo Diniz-Pereira (1999, p. 117), é “[...] importante, ainda, pensar a formação de um professor que compreenda os fundamentos das ciências e revele uma visão ampla dos saberes". Além disso, é essencial a formação de um profissional crítico, que valorize os saberes da prática docente, por meio da reflexão e da análise do saber teórico e da prática.

A problemática deste estudo aflorou a partir das vivências como docente da área de Estágio Supervisionado, do Curso de Licenciatura em Educação do Campo/Ciências da Natureza (LEdoC), do Campus Amílcar Ferreira Sobral (CAFS), da Universidade Federal do Piauí (UFPI). O campus fica localizado no município de Floriano (PI), situado na região sul do Estado do Piaú, a $260 \mathrm{~km}$ da capital Teresina. É a quinta cidade mais rica do estado, sendo uma referência no setor de saúde, comércio e na educação, com 3 (três) universidades públicas (um Instituto Federal, uma Universidade Federal e uma Universidade Estadual) e diversas Faculdades particulares.

Assim, o presente estudo objetiva compreender a importância do Estágio Supervisionado para a formação de professores do campo, do curso de Licenciatura em Educação do Campo/Ciências da Natureza, do CAFS/UFPI. A análise e a reflexão do Estágio Supervisionado na LEdoC/CAFS está integrada à tríade ensino, pesquisa e extensão, de forma a possibilitar ao aluno estagiário refletir sobre sua prática durante e depois do estágio, ao tempo que permite ao futuro professor, tornar-se pesquisador de sua prática.

No âmbito da LEdoC/CAFS, os estágios são realizados em escolas do campo, como também, da zona urbana (pois recebem muitos alunos da zona rural). A atuação dos futuros professores do campo está pautada no Decreto de n. 7.352, de 04 de novembro de 2010, o qual dispõe que a Educação do Campo deve ser compreendida de acordo com a realidade do povo camponês, para que possam ter como direito uma educação digna e de qualidade, sendo condizente com seus interesses e necessidades (BRASIL, 2010).

$\mathrm{Na}$ LEdoC/CAFS, por ser um curso da modalidade Ciências da Natureza, o Estágio Supervisionado é realizado na área de Ciências nos anos finais do Ensino Fundamental $\left(6^{\circ}\right.$ ao $9^{\circ}$ ano) e no Ensino Médio, nas disciplinas de Física, Química e Biologia. Essa etapa da formação oportuniza aos futuros professores construir saberes, habilidades e competências para o ofício da docência, experienciando diversas situações da prática docente no ensino de Ciências. 
Os dados da pesquisa são oriundos da caracterização do Estágio Supervisionado na LEdoC/CAFS e na análise dos relatos de experiência apresentados pelos alunos nas disciplinas de Estágio Supervisionado II e IV. Estes revelam a importância dessa etapa na formação de professores do campo, pois possibilita que reflitam sobre a prática, articulando saberes teóricos e da docência, auxiliando na tomada de decisões e resolução de problemas no contexto escolar.

\section{REFLEXÕES ACERCA DO ESTÁGIO SUPERVISIONADO}

As discussões acerca do Estágio Supervisionado são frequentes ao discutirmos sobre a formação docente. Sendo um dos componentes curriculares presente em qualquer curso de formação inicial de professores, ele é definido na Lei no ${ }^{\circ} 11.788 / 2008$, em seu Art. $1^{\circ}$, como sendo um:

[...] ato educativo escolar supervisionado, desenvolvido no ambiente de trabalho, que visa à preparação para o trabalho produtivo de educandos que estejam frequentando o ensino regular em instituições de educação superior, de educação profissional, de ensino médio, da educação especial e dos anos finais do ensino fundamental, na modalidade profissional da educação de jovens e adultos. (BRASIL, 2008, p. 01)

Ou seja, o estágio proporciona o contato direto do futuro docente com seu campo de atuação profissional e a realidade escolar. Neste sentido, a prática do estágio, nos dias de hoje, aponta para a necessária articulação da formação inicial com a prática profissional, devendo constituir-se em momento de experiências importantes, em que o professor pode construir seu reservatório de saberes teóricos e práticos necessários à atuação profissional.

[...] teoria e prática passam a ser consideradas como elementos indissociáveis da atividade docente, uma vez que, para se refletir sobre seu trabalho, sobre sua ação e sobre as condições sociais e históricas de sua prática, o professor precisa de referenciais teóricos que lhe possibilitem uma melhor compreensão e aperfeiçoamento de sua atividade educativa. (LEITE, 2008, p. 10)

O Estágio Supervisionado, conforme define a Lei n. 11.788, de 25 de setembro de 2008, no seu Art. $1^{\circ}$, consiste no ato educativo escolar supervisionado, com vistas à preparação para $\mathrm{O}$ trabalho produtivo de educandos cursando o ensino regular nas Instituições de Educação Superior (IES), de Educação Profissional, de Ensino Médio, da Educação Especial e dos anos finais do Ensino Fundamental, na modalidade profissional da Educação de Jovens e Adultos (BRASIL, 2008). 
Conforme consta no Art. $1^{\circ}$, parágrafo $2^{\circ}$, da referida lei, o estágio é um momento importante para a vida do estudante de licenciatura, pois promove o aprendizado de competências da atividade profissional, além da contextualização curricular, com o objetivo de desenvolver o educando para a vida cidadã e para o trabalho (BRASIL, 2008). Ou seja, é um componente curricular obrigatório que deve proporcionar experiências que contribuam com a construção das variadas formas dos saberes para ensinar nas mais adversas situações de ensino e aprendizagem. Sendo assim, o estágio possibilita ao futuro profissional em seu campo de atuação, a oportunidade de entender melhor o ofício da profissão, ser professor e suas principais atribuições.

Ainda conforme a referida Lei, o estágio deve se desenvolver a partir do início da segunda metade do curso, reservando-se um período final para a docência compartilhada, sob a supervisão da escola de formação. Por isso, na maioria dos cursos de licenciatura, os estágios se iniciam a partir do $4^{\circ}$ período, sempre contando com um professor orientador na universidade e um professor supervisor na escola.

Pimenta; Lima (2004, p. 120) afirmam que "o estágio tem por objetivo preparar o estagiário para a realização de atividades na escola, como professores na sala de aula, bem como para a análise, avaliação e crítica". É durante o estágio que o futuro professor terá contato com a realidade na qual atuará. Portanto, caracteriza-se como um momento de atuação do processo educativo, sendo um elemento fundamental para a formação e constituindo-se como o espaço, por excelência, da relação dialética entre a teoria e a pratica.

Esse campo tão vasto de formação caracteriza-se como mediação entre professores formadores, estudantes dos cursos de licenciatura e os professores supervisores das escolas, interagindo constantemente nesse processo de formação. Dessa forma, Marques (2000, p. 236) aponta que "o estágio Supervisionado é parte do currículo da Universidade que serve como aproximação da realidade que cada novo profissional irá vivenciar, bem como, uma reflexão de sua atuação como agente transformador na sociedade". Ou seja, o estágio proporciona aos alunos uma complementação educacional e profissional, que permite conhecer sua futura profissão, sendo essencial no desenvolvimento de competências para o exercício profissional.

Há também, uma preocupação com as condições de realização do Estágio, quanto ao local e ao desenvolvimento das atividades, que exige compromisso e responsabilidade do aluno estagiário nessa etapa da formação docente. Para Grangeiro (2008, p. 10):

[...] conhecer a realidade onde desempenhará sua escolha profissional, e refletir sobre o que se encontra na prática, abrindo espaço para a proposição de soluções fundamentadas na teoria e, sem dúvida, um grande estímulo à capacidade crítica e criativa do estagiário. Por essas razões, valorizamos o papel importante do estágio na formação e no desempenho da prática profissional. 
O conhecimento da realidade do local de atuação do estágio é crucial, para que o futuro professor possa lidar com as diversas situações que surgem no cotidiano da sua atuação na escola, desenvolvendo a capacidade crítica e criativa de resolução de problemas e tomada de decisões no processo de ensino e aprendizagem.

As novas Diretrizes Curriculares Nacionais para a formação inicial em nível superior, instituída pela Resolução n. 02/2015, trazem o Estágio Curricular Supervisionado como componente obrigatório da organização curricular das licenciaturas, sendo uma atividade específica intrinsecamente articulada com a prática e com as demais atividades de trabalho acadêmico. Segundo a resolução, devem ser dedicadas no mínimo 400 (quatrocentas) horas para o Estágio Supervisionado, “[...] na área de formação e atuação na educação básica, contemplando, também, outras áreas específicas, se for o caso, conforme o projeto de curso da instituição" (BRASIL, 2015, p. 11).

No contexto dos cursos de licenciatura da UFPI, o Estágio Supervisionado Obrigatório está regulamentado pelas Leis Federais, dentre elas: a LBD n. 9.394/96; a Lei n. 11.788/2008, além da Resolução CEPEX/UFPI n. 177/2012. Conforme afirmam as legislações vigentes, constitui uma atividade educativa que visa à preparação para o trabalho produtivo, ou ainda, é o momento de aprendizagem em que se aprende a partir da prática, o ofício da profissão.

Portanto, é no estágio que se inicia o processo de formação da identidade profissional do professor. Essa vivência permite a construção da sua prática, atuando ativamente na elaboração, execução e avaliação do seu trabalho como docente (PIMENTA; LIMA, 2004). Ou seja, o processo de construção do ser professor é contínuo, perpassa o chão da escola, os saberes da docência, as experiências trazidas para a formação, as aprendizagens construídas no curso de formação inicial, as interações com a escola e professores e suas reflexões sobre sua prática como professor.

Logo, o estágio permite que futuro profissional da Educação do Campo refletir sobre seu ambiente de trabalho, pensar abertamente sobre a educação que vem sendo oferecida aos alunos, proporcionando uma reflexão acerca da construção de uma educação democrática.

\section{METODOLOGIA}

Para o desenvolvimento deste estudo, pautamo-nos na pesquisa qualitativa. Segundo Oliveira (2012, p. 59), a pesquisa qualitativa é aquela que busca "explicar em profundidade o significado e as características do resultado das informações obtidas através de entrevistas ou questões abertas, sem a mensuração quantitativa de características ou comportamentos". Ou seja, 
é aquela que considera o ser social e seus atos, através da interpretação de suas ações, a partir de uma realidade vivida e partilhada, preocupando-se com as singularidades que permeiam as relações constitutivas da realidade.

No Projeto Político-Pedagógico da LEdoC/CAFS está previsto a realização de 4 (quatro) estágios, desenvolvidos a partir da metade do curso (Figura 1 ), realizado do $5^{\circ}$ ao $8^{\circ}$ período, em escolas do campo e também, da zona urbana, no município de Floriano (PI) e cidades circunvizinhas (UFPI, 2013). Os estágios totalizam uma carga horária de 405 horas/aula, conforme as legislações vigentes.

Figura 1: Estágios Supervisionados desenvolvidos na LEdoC/CAFS/UFPI
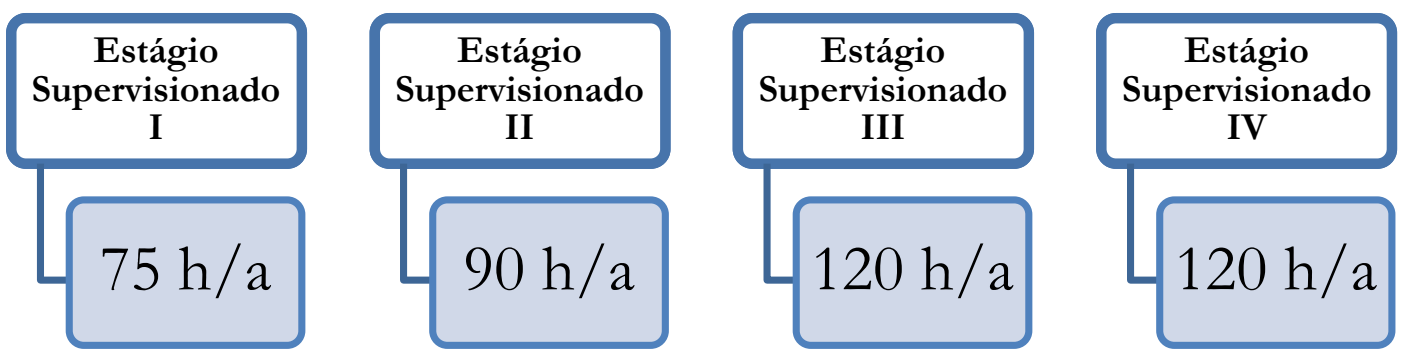

Fonte: Elaborado pelas autoras (2020)

No Estágio Supervisionado I é realizada a observação da gestão e da prática docente no Ensino Fundamental e Médio. Temos também, o desenvolvimento de oficinas de planejamento da ação docente e discussões acerca do processo de formação e a trajetória da profissionalização docente. No Estágio Supervisionado II, acontecem as regências na área de Ciências, nos anos finais do Ensino Fundamental. Os Estágios Supervisionados III e IV abrangem a regência no Ensino Médio, nas disciplinas de Física, Química e Biologia.

Nesse contexto, Pimenta; Lima (2005, p. 06) destacam que:

[...] o estágio se constitui como um campo de conhecimento, o que significa atribuir-lhe um estatuto epistemológico que supera sua tradicional redução à atividade prática instrumental. Enquanto campo de conhecimento, o estágio se produz na interação dos cursos de formação com o campo social no qual se desenvolvem as práticas educativas. Nesse sentido, o estágio poderá se constituir em atividade de pesquisa.

Dessa forma, o estágio de regência é então, uma prática, onde o futuro professor vai relacionar o que aprendeu na teoria com a prática vivenciada no contexto escolar. Nesse momento, 
cabe ao estagiário, analisar o que acontece diante da realidade da educação vigente, desenvolvendo seu próprio modus operandi da prática docente.

Neste estudo, o lócus de investigação são as disciplinas de Estágio Supervisionado II e IV da LEdoC/CAFS, no qual buscamos compreender a importância do Estágio Supervisionado para a formação de professores do campo, com base nos relatos de experiência desenvolvidos pelos alunos estagiários. No estudo, utilizamos como instrumentos de coleta de dados, os relatos de experiências apresentados nas disciplinas e a avaliação do desempenho dos alunos nas escolas campo durante a realização dos estágios. A análise e a interpretação dos dados seguem um movimento contínuo, realizado concomitantemente, à luz do referencial teórico da pesquisa.

\section{RESULTADOS E DISCUSSÃO}

Apresentamos a análise dos relatos de experiência vivenciada pelos alunos nas disciplinas de Estágio Supervisionado II e IV, do curso de Licenciatura em Educação do Campo/Ciências da Natureza, do CAFS/UFPI. Trazemos os recortes dos relatos de 3 alunos do Estágio Supervisionado II (Relatos 1, 2 e 3) e 3 alunos do Estágio Supervisionado IV (Relatos 4, 5 e 6).

Os dados revelam que os futuros professores realizam uma reflexão sobre sua prática no estágio, identificando as dificuldades encontradas nesse momento, bem como as possíveis soluções.

\footnotetext{
O estágio é de suma importância, pois permite ao estagiário vivenciar um momento crucial de sua formação, nos proporcionando elementos para reflexão acerca das condicionantes que envolvem a atuação do professor de ciências da natureza, bem como acerca da sua própria formação acadêmica. (RELATO 1)
}

A experiência vivenciada no estágio permite ao aluno avaliar todo conbecimento adquirido em sala de aula nas universidades, fazendo o mesmo, refletir sobre quais praticas escolher para o futuro, como agir em sala de aulas com os adolescentes. (RELATO 2)

Compreendendo que o estágio é um espaço privilegiado de aprendizado e parte importante do processo de formação docente, a experiência vivenciada favoreceu a descoberta de aspectos que devem ser considerados e, portanto, observados por aqueles (as) que almejam por vocação ou por opção, o exercício da prática docente. (RELATO 4)

O que aprendamos no cotidiano da escola, nos remete a uma reflexão de que é preciso fazer mais e diferente para que as transformações sociais aconteçam a partir dos debates dos acontecimentos que estão na escola e ao entorno da comunidade. (RELATO 5)

Desse modo, concordamos com Ghedin; Oliveira; Almeida (2015, p. 176) ao afirmarem que "a prática reflexiva, a partir da pesquisa e investigação na própria prática, constitui um processo dialético de geração da prática a partir da teoria e da teoria a partir da prática”. Ou seja, através da pesquisa, há uma ressignificação das práticas, uma reelaboração do conhecimento, que 
proporcionará ao aluno estagiário compreender e reinterpretar o mundo e a realidade, propondo novas formas de agir e ser.

Através da pesquisa, o futuro professor desenvolve o espírito científico, buscando respostas para os problemas que surgem nas atividades de ensino, ou seja, na prática educativa. Essa forma de reinterpretar a realidade possibilita compreender o mundo e a realidade, propondo novas formas de agir e ser (GHEDIN; OLIVEIRA; ALMEIDA, 2015). No âmbito da escola, a reflexão sobre a prática proporciona a adoção de novas metodologias e ferramentas didáticopedagógicas, que poderá se revelar como espaço propício para a investigação da realidade.

Acerca das regências, destacamos alguns relatos dos alunos da LEdoC/CAFS, nesse momento de atuação profissional e mobilização dos saberes docentes.

As atividades desenvolvidas durante todas as regências tiveram o mesmo propósito, afim de promover, interação e autonomia entre os alunos, assim como as atividades, seminários que motivou as açôes conjuntas dos alunos, uma vez que eles se sentem parti de um grupo. (RELATO 1)

As regência durante o estágio nos proporcionaram experiência que geraram responsabilidades e compromissos com os alunos como na educação. De início houve a insegurança de como atuar na sala de aula, mas buscamos articular a teoria adquirida com a prática vivenciada. (RELATO 5)

O contato direto com os alunos na regência das disciplinas de Química, Biologia e Física, foi um grande desafio, bastante engrandecedor no que diz respeito, a relação ensino e aprendizagem, abrindo novos horizontes tanto para a mim (estagiária) quanto aos demais alunos da escola. (RELATO 6)

Sobre os estágios de regência, Carvalho (2012, p. 66) afirma que "um dos principais objetivos desse tipo de estágio é fazer com que nossos alunos aproveitem os estágios para testar, como professores, as inovações que discutiram teoricamente na universidade e/ou observaram com os bons professores da escola básica", proporcionando ao aluno-estagiário uma experimentação didática, dando condições para que ele desenvolva um olhar investigativo, da sua própria prática pedagógica. Logo, o apoio do professor supervisor é essencial para acompanhar o aluno-estagiário em sala de aula, oferecendo-lhe suporte didático e, até mesmo, para o aluno sentir segurança na escola.

Destacamos que as escolas em que os alunos da LEdoC/CAFS realizam estágio não são apenas no município de Floriano (PI), mas nos municípios circunvizinhos, das quais destacamos: Nazaré do Piauí (PI), Sebastião Leal (PI), Francisco Aires (PI), Barão de Grajaú (MA). Isso porque, os alunos podem realizar seus estágios nas escolas próximas as suas comunidades, possibilitando uma maior adaptação do aluno-estagiário na escola do campo. 
Os alunos que já passaram pelos quatro estágios, ao final da disciplina de Estágio Supervisionado IV compreendem a importância dessa etapa formativa, como podemos perceber nos relatos a seguir:

Diante das experiências oportunizadas pelos estágios percebemos o verdadeiro significado e necessidade de um professor estagiário em sala de aula, pois enquanto estagiária conseguir enfrentar as dificuldades que surgem no meio educacional na área de Ciências da Natureza das escolas do campo, bem como torná-las consciente de que devemos pelo menos tentar mudar a realidade do ensino e aplicar métodos pedagógicos mais adequados, para satisfazer a necessidade de todos os alunos. (RELATO 4)

[...] Ao término dos estágios ficou claro a importância de entender a realidade da escola do campo e também conhecer a realidade da escola pública, como também aprimorar o conhecimento que permeia nossa área de ensino. (RELATO 5)

A realização do estágio me possibilitou vivenciar situações diversas nas escolas do campo, sendo essenciais para minha preparação como futuro docente. Durante os estágios foi possivel experimentar os desafios da profissão, ou seja, tomada de atitudes imediatas, em função da ocorrência de situações inesperadas (falta de energia elétrica durante a aula, interrupção da aula por conta de outra necessidade da escola, falta de material didático, até livros, dentre outras). (RELATO 6)

Essa tomada de consciência deve apontar e caminhar em vista de uma educação transformadora, que seja verdadeiramente capaz de contribuir para a construção de uma sociedade onde a cidadania não seja privilégio de uns poucos, mas um direito de cada pessoa. Alarcão (2011) corrobora esse pensamento, ao afirmar a importância das relações interpessoais para o fazer docente, na construção dos saberes necessários a sua ação no cotidiano escolar.

Ou seja, esse processo de construção da identidade profissional começa na formação inicial e perpassa pela carreira docente, se desenvolvendo ao longo da sua vida profissional, através das práticas vivenciadas no dia a dia e com experiência de vida. Por isso, é durante o estágio que o aluno vivencia o exercício da profissão, através do contato direto com o cotidiano escolar, ao tempo que contribui para o seu desenvolvimento integral como pessoa e profissional.

Logo, a formação de professores deve oferecer condições para um desenvolvimento pessoal e profissional mediante à aquisição de saberes que favoreçam a busca por respostas às necessidades reais colocadas pela ação educativa. A discussão acerca da competência técnica do professor se apresenta como imperativo, visto que a dignidade do ser professor pode ser mantida na construção da identidade profissional, que passa necessariamente por essa questão.

Ressaltamos que os desafios para uma educação libertadora e transformadora, ainda são muitos. Portanto, necessitamos de um esforço coletivo no enfrentamento e busca de soluções na Educação do Campo, assim como a formação específica de docentes para atuarem nas escolas do campo. Essa é uma necessidade que urge em meio à realidade precária de nossas escolas e da 
necessidade de profissionais qualificados e potencialmente capazes de contribuir para o desenvolvimento das nossas comunidades.

Portanto, durante o estágio há uma ressignificação das práticas desenvolvidas, quando se trabalha na perspectiva da pesquisa. Nesse processo, o estagiário desenvolve ações de reflexão sobre sua prática, sendo um pesquisador dela, valorizando a autonomia, a capacidade de resolução de problemas, tomada de decisões e promovendo o desenvolvimento de sua formação profissional.

\section{CONSIDERAÇÕES FINAIS}

O Estágio Supervisionado é o momento de aprendizagem da docência. Neste sentido, é indispensável como componente curricular dos cursos de licenciatura, uma vez que, o graduando necessita se preparar para se inserir no seu campo de atuação profissional. A finalidade dessa etapa é, portanto, proporcionar ao aluno, uma aproximação com a realidade na qual ele atuará.

O estágio, sob a forma supervisionada, consiste numa importante fase da vida acadêmica, pois é um dos momentos de integração entre a universidade, a escola e a comunidade. É nesse momento que o licenciando começa a perceber como tornar-se um sujeito ativo no processo educacional e social, proporcionando uma inserção no campo de atuação profissional.

O Estágio Supervisionado no Curso de Licenciatura em Educação do Campo/Ciências da Natureza, tem buscado formar um professor do campo capaz de conhecer a teia de relações que há no espaço escolar; conhecer a dinâmica das instituições de ensino; compreender os limites e as possibilidades para o desenvolvimento do trabalho pedagógico; valorizar os conhecimentos e a cultura campesina; articular conteúdos científicos aos saberes da comunidade; desenvolver um olhar sensível do processo ensino e aprendizagem; além de encontrar caminhos e possibilidades condizentes com a realidade e as necessidades da escola do campo.

A atuação do professor do campo da LEdoC/CAFS é bastante abrangente, devido à modalidade de Ciências da Natureza. Como já mencionamos, o professor é habilitado para o ensino de Ciências, dos anos finais do Ensino Fundamental e para as disciplinas de Biologia, Física e Química, do Ensino Médio. Esse aspecto exige mais dedicação e estudo por parte dos alunos, pois são poucas as disciplinas do curso voltadas para as áreas especificas de Física e Química, ponto que gera maior dificuldade no momento da regência.

Por isso, os relatos de experiência nos possibilitaram compreender que o Estágio Supervisionado consiste em uma etapa essencial da formação docente, onde o aluno reafirma, ou não, a sua escolha pela docência. Em outras palavras, esse choque de realidade ao entrar no estágio desperta no futuro professor um universo de sentimentos, incertezas, medos, insegurança que são 
superados (ou não) ao longo do desenvolvimento dessa etapa formativa.

Através das visitas às escolas do campo, durante o acompanhamento do Estágio Supervisionado, percebemos que a educação nas escolas do campo sofre com a falta de transporte escolar para deslocamento dos alunos as escolas, falta de infraestrutura nas escolas, pouca participação das famílias pela educação escolar dos filhos, a baixa motivação dos alunos para aprender, a predominância de aulas expositivas e a resistência de alguns profissionais da educação em fazerem um trabalho eficiente e eficaz.

Por isso, é preciso cada vez mais aproximar universidade e escola, no sentido de melhorar a qualidade da educação escolar dos educandos, com a participação efetiva da comunidade para o resgate dos valores sociais, culturais e históricos. Além disso, é preciso incentivar os professores a atuarem nas escolas do campo, ressaltando a importância do Estágio Supervisionado, no sentido de fortalecer a docência e a construção da identidade docente de professores da educação do campo.

Logo, faz-se necessário que essa etapa formativa seja preparada com a finalidade de minimizar as dificuldades encontradas pelos alunos na realização do estágio. Ressaltamos também, a importância do professor supervisor nesse processo, essencial no acompanhamento do aluno na sala de aula, proporcionando-lhe segurança durante sua atuação na escola.

A importância deste estudo reflete no processo de formação dos professores do campo e como essa educação vem sendo ofertada aos alunos das comunidades campesinas, proporcionando-nos uma reflexão necessária para a construção de uma educação igualitária, principalmente, quando levamos em consideração a valorização dos saberes de todos os indivíduos.

Os resultados da pesquisa contribuirão para o desenvolvimento de outros estudos que se voltem para o Estágio Supervisionado na formação de professores do campo, focalizando suas especificidades e potencialidades, com o encaminhamento de propostas, considerando as limitações e as dificuldades que o curso enfrenta.

\section{REFERÊNCIAS}

ALARCÃO, Isabel. Professores reflexivos em uma escola reflexiva. 7. ed. São Paulo: Cortez, 2011.

BRASIL. Resolução n. 2, de $1^{\circ}$ de julho de 2015. Define as Diretrizes Curriculares Nacionais para a formação inicial em nível superior (cursos de licenciatura, cursos de formação pedagógica para graduados e cursos de segunda licenciatura) e para a formação continuada. Diário Oficial da União, Brasília, DF, de 2 de jul. 2015. Disponível em: < http://portal.mec.gov.br/docman/agosto-2017-pdf/70431-res-cne-cp-002-03072015-pdf/file $>$. Acesso em: 22 abr. 2020. 
BRASIL. Decreto-lei n ${ }^{\circ} 7352$, de 04 de novembro de 2010. Dispõe sobre a política de educação do campo e o Programa Nacional de Educação na Reforma Agrária - PRONERA. Diário Oficial da União, Brasília, DF, 04 nov. 2010. Disponível em: < htt://portal.mec.gov.br/docman/marco-2012-pdf/10199-8-decreto-7352-de4-de-novembro-de2010/file >. Acesso em: 22 abr. 2020.

BRASIL. Lei no 11.788, de 25 de setembro de 2008. Dispõe sobre o estágio de estudantes dentre outras providências. Diário Oficial da União, Brasília, DF, 26 set. 2008. Disponível em: < http://www.planalto.gov.br/ccivil_03/_ato2007-2010/2008/lei/111788.htm >. Acesso em: 30 abr. 2020.

CARVALHO, Ana Maria Passos de. Os Estágios nos cursos de licenciatura. São Paulo: Cengage Learning, 2012.

DINIZ-PEREIRA, Júlio Emílio. As licenciaturas e as novas políticas educacionais para a formação docente. Educação \& Sociedade, Campinas, ano 20, n. 68, p. 109-125, dez., 1999.

GRANGEIRO, Manuela Fonseca. O estágio na formação tecnológica. In: XIV Encontro Nacional de Didática e Prática de Ensino (ENDIPE), 14, 2008, Rio Grande do Sul. Anais... Rio Grande do Sul: UNISINOS, 2008.

GHEDIN, Evandro; OLIVEIRA, Elisângela Silva de; ALMEIDA, Whasgton. A. de. Estágio com pesquisa. São Paulo: Cortez, 2015.

GONCALVES, Eloísa Dias. A contribuição dos movimentos sociais para a efetivação da educação do campo: a experiência do programa nacional de educação na reforma agrária.

Educação e Sociedade, Campinas, v. 37, n. 135, p. 371-389, abr-jun., 2016. Disponível em: < https://www.scielo.br/pdf/es/v37n135/1678-4626-es-37-135-00371.pdf >. Acesso em 22 abr. 2020.

LEITE, Yoshie Ussami Ferrari. A construção dos saberes docentes nas atividades de estágio nos cursos de licenciatura. In: Encontro Nacional de Didática e Prática de Ensino (ENDIPE). Anais... PUC, Rio Grande do Sul, 2008.

MARQUES, Mário Osório. A formação do profissional da educação. Ijuí: UNIJUI, 2000.

OLIVEIRA, Maria Marly de. Como fazer pesquisa qualitativa. 4. ed. Petrópolis: Vozes, 2012.

PIMENTA, Selma Garrido; LIMA, Maria Socorro Lucena. Estágio e docência: diferentes concepções. Revista Poíesis, v. 3, n. 3 e 4, p. 5-24, 2005/2006.

PIMENTA, Selma Garrido; LIMA, Maria Socorro Lucena. Estágio e docência. São Paulo: Cortez, 2004.

UNIVERSIDADE FEDERAL DO PIAUÍ. Conselho de Ensino, Pesquisa e Extensão (CEPEX). Resolução n. 177, de 5 de novembro de 2012. Aprova a atualização das normas de funcionamento dos cursos de graduação da UFPI e dá outras providências. Universidade Federal do Piauí. Teresina, 2012. Disponível em: <

http://leg.ufpi.br/subsiteFiles/proreitoriapreg/arquivos/files/resolucao\%20preg 20 12(1).PDF >. Acesso em: 19 abr. 2020. 
UNIVERSIDADE FEDERAL DO PIAUÍ. Conselho de Ensino, Pesquisa e Extensão da Universidade Federal do Piauí. Projeto Pedagógico do Curso Graduação, Licenciatura em Educação do Campo. Programa de Apoio à Formação Superior em Licenciaturas em Educação do Campo. Universidade Federal do Piauí. Campus Amílcar Ferreira Sobral, Floriano, 2013. 